\title{
- OPEN ACCESS \\ Clinical aspects of incorporating cord clamping into stabilisation of preterm infants
}

\author{
Ronny Knol, ${ }^{1}$ Emma Brouwer, ${ }^{2}$ Alex S N Vernooij, ${ }_{1}^{3}$ Frans J C M Klumper, ${ }^{4}$ \\ Philip DeKoninck, ${ }^{5,6}$ Stuart B Hooper, ${ }^{6}$ Arjan B te Pas ${ }^{2}$
}

\begin{abstract}
${ }^{1}$ Division of Neonatology, Department of Paediatrics, Erasmus University Medical Centre, Rotterdam, ZuidHolland, The Netherlands 'Division of Neonatology, Department of Paediatrics, Leiden University Medical Centre, Leiden, The Netherlands ${ }^{3}$ Department of Medical Engineering, Leiden University Medical Centre, Leiden, The Netherlands

${ }^{4}$ Department of Obstetrics, Leids Universitair Medisch Centrum, Leiden, Zuid-Holland, The Netherlands

${ }^{5}$ Department of Obstetrics and Gynaecology, Erasmus University Medical Centre, Rotterdam, The Netherlands ${ }^{6}$ The Ritchie Centre, Hudson Institute of Medical Research, Monash University, Clayton, Victoria, Australia
\end{abstract}

\section{Correspondence to} Dr Ronny Knol, Division of Neonatology, Department of Paediatrics, Erasmus University Medical Centre, PO Box 2060, Rotterdam 3000 CB, The Netherlands; r.knol@ erasmusmc.n

Received 9 February 2018 Revised 31 March 2018 Accepted 2 April 2018 Published Online First 21 April 2018

Check for updates

To cite: Knol R, Brouwer $\mathrm{E}$, Vernooij ASN, et al. Arch Dis Child Fetal Neonatal Ed 2018;103:F493-F497.

\section{ABSTRACT}

Fetal to neonatal transition is characterised by major pulmonary and haemodynamic changes occurring in a short period of time. In the international neonatal resuscitation guidelines, comprehensive recommendations are available on supporting pulmonary transition and delaying clamping of the cord in preterm infants. Recent experimental studies demonstrated that the pulmonary and haemodynamic transition are intimately linked, could influence each other and that the timing of umbilical cord clamping should be incorporated into the respiratory stabilisation. We reviewed the current knowledge on how to incorporate cord clamping into stabilisation of preterm infants and the physiologicalbased cord clamping (PBCC) approach, with the infant's transitional status as key determinant of timing of cord clamping. This approach could result in optimal timing of cord clamping and has the potential to reduce major morbidities and mortality in preterm infants.

\section{INTRODUCTION}

Fetal to neonatal transition is characterised by major pulmonary and haemodynamic changes occurring in a short period of time. There are two interventions where the caregiver can largely influence these changes: (1) applying respiratory support when there is difficulty breathing at birth and (2) timing of cord clamping. The best way to support pulmonary transition has always been a focus of the international resuscitation guidelines, and comprehensive recommendations are available. ${ }^{12}$ However, recommendations on timing of cord clamping only received significant attention in the more recent guidelines.

Although umbilical cord clamping is a quick and simple intervention, the timing of cord clamping may have a large impact on the infants' health. While it is thought that the major benefit of delayed cord clamping (DCC) is placental transfusion (blood from placenta to the infant), ${ }^{3}$ it is now evident that there are many benefits. ${ }^{4}$ Although cord clamping and stabilisation are commonly considered as two seprate interventions, ${ }^{5}$ recent experimental studies demonstrated that pulmonary and haemodynamic transition are intimately linked. ${ }^{67}$ In healthy term infants, pulmonary transition establishes soon after birth, but apnoeic term infants and preterm infants often need respiratory support to aerate their lungs adequately. ${ }^{8}$ Evidence is emerging that it might be beneficial to wait with cord clamping until the pulmonary transition (ie, lung aeration) has been established. ${ }^{9}{ }^{10}$ As a consequence, timing of cord

\section{What is already known on this topic?}

- Delayed cord clamping is beneficial for term and preterm infants and is recommended in current clinical guidelines.

- Preterm infants requiring stabilisation or resuscitation at birth generally are excluded from delayed cord clamping.

- Experimental studies have shown positive effects if respiratory support is started prior to umbilical cord clamping.

\section{What this study adds?}

Multiple practical issues must be addressed before cord clamping can be incorporated into stabilisation of preterm infants.

- Using the infant's transitional status as key determinant for the timing of cord clamping may result in true physiological-based cord clamping (PBCC)

- PBCC may be able to reduce major morbidities and mortality in preterm infants.

clamping should be incorporated into strategies for stabilising the infant. In this review, we will describe what is currently known about the clinical aspects of integrating cord clamping in the stabilisation of infants at birth.

\section{NEWBORN TRANSITION AND CORD CLAMPING DCC: benefits and placental transfusion}

The method of immediate cord clamping (ICC) after delivery of the child became routine in the 1960 s, as it was widely introduced as a package of care for reducing maternal postpartum haemorrhage. ${ }^{11}$ However, review of the data showed that only the uterotonic drug accounted for this effect and ICC did not have any additional benefit. ${ }^{12}$ In the last two decades, multiple randomised clinical trials comparing immediate and DCC in term and preterm infants have been conducted. In most of the trials in healthy term infants, early clamping was within $15 \mathrm{~s}$ of birth, but timing of delayed clamping varied considerably between $1 \mathrm{~min}$ and $5 \mathrm{~min}$ after delivery, and infants who needed some support or resuscitation were excluded in all trials. ${ }^{13}$ The main beneficial effect of delaying cord clamping has been ascribed to placental transfusion from the placenta to the newborn infant. ${ }^{14}$ The most important clinical 
outcome observed in term infants was a decreased incidence of iron deficiency at the age of 3-6 months after DCC, ${ }^{13}$ prompting the WHO to recommend DCC in all births. ${ }^{15}$ However, the question of optimal timing of cord clamping is still unanswered, especially in the infants that need support or resuscitation during transition. ${ }^{9}$

DCC in preterm infants also had a beneficial effect, leading to increased haemoglobin levels and less blood transfusions. ${ }^{16}$ Moreover, DCC seemed to support preterm circulatory transition in decreasing the incidence of low blood pressure and the need for inotropes during the first postnatal days. ${ }^{17}$ A Cochrane meta-analysis of small trials in preterm infants showed a reduction in the risk ratio for intraventricular haemorrhages (IVHs) and necrotising enterocolitis (NEC) when cord clamping was delayed. ${ }^{18}$ However, the recent large Australian Placental Transfusion Study trial in 1566 preterm infants did not confirm the beneficial effects of DCC on these morbidities. ${ }^{19}$ Nonetheless, a recent meta-analysis including the APTS trial clearly showed that DCC reduced hospital mortality in preterm infants. ${ }^{20}$

The debate on the optimal timing of cord clamping for placental transfusion is still ongoing. In the available trials, timing ranged between $30 \mathrm{~s}$ and more than $5 \mathrm{~min}$, or sometimes until cessation of cord pulsations. Although Yao et al concluded in their studies that placental transfusion is completed in $2-3 \mathrm{~min}$ and flow in arterial umbilical arteries stops after $30-45 \mathrm{~s}$, recent studies reported conflicting results. ${ }^{1421}$ It has become more evident from experimental and observational studies that placental perfusion probably continues for much longer. The driving force for placental venous return to the fetus and newborn infant is then largely determined by the arterial flow towards the placenta. The mechanism of the placental transfusion is not clear, but as blood volumes have not been measured before birth, it is possible that volumes are reduced during labour and that placental transfusion reflects a restoration of disturbed blood volume between placenta and fetus after birth. ${ }^{22}$

\section{Factors influencing placental transfusion}

Several factors potentially influencing the amount of placental transfusion have been the subject of research, such as the position of the baby during DCC, the timing of the administration of a uterotonic drug and the mode of delivery. Yao et $a l^{23}$ observed that gravity might be important if the infant is held extremely above or below the introitus with the cord intact. However, Vain et al recently demonstrated in a large randomised trial that the position of a term infant before cord clamping does not affect the volume of placental transfusion. ${ }^{24}$ This is supported by a recent experimental study demonstrating that changing the body position of preterm lambs before cord clamping has minimal effect on umbilical and cerebral blood flow. ${ }^{21}$ In fact, a much greater effect on umbilical flows and haemodynamic parameters was achieved by initiating ventilation before clamping.

There are no randomised clinical trials available investigating the timing of uterotonic drug administration and cord clamping. Subgroup analysis in the Cochrane Review on DCC could not be performed because of major heterogeneity between the available studies. ${ }^{13}$ Estimating the clinical effect of mode of delivery (vaginal delivery vs caesarean section) proved to be difficult in the meta-analyses, as the estimable data were not available or badly reported. ${ }^{13} 18$ Current clinical guidelines do not differentiate in their recommendations between various modes of delivery.

Umbilical cord milking has been proposed as a substitute for DCC and indeed seems to have a positive effect on haematological parameters and IVH. ${ }^{25}$ However, from a physiological perspective, larger swings in the amount of blood returning from the placenta during cord milking is not the most logical method to pursue and is contradictive to the presumed more gradual circulatory transition during DCC. Recent experiments in preterm lambs showed a lack of placental transfusion during umbilical cord milking, accompanied by considerable haemodynamic disturbances. $^{26}$

\section{Physiological-based cord clamping (PBCC)}

While Yao et al demonstrated that placental transfusion is complete in most term infants at $3 \mathrm{~min},{ }^{14}$ most DCC trials in preterm infants used a shorter cord clamping time of 30-60 s. Moreover, in these studies, only preterm infants who were adequately breathing were included and those needing stabilisation or resuscitation were excluded, thereby potentially excluding infants that would benefit most. Thus, developing an approach that includes infants needing support and potentially optimises the placental transfusion could increase the beneficial effects. ${ }^{27}$ In addition to the placental transfusion, recent experimental studies have demonstrated haemodynamic benefits of waiting with cord clamping until the lungs are aerated and the infant has stabilised. ${ }^{28}$

The haemodynamic changes that occur during the transition period immediately after birth are closely related to lung aeration and pulmonary perfusion. ${ }^{22}$ The fetal circulation is characterised by a high pulmonary vascular resistance and a low placental vascular resistance. ${ }^{29}$ Depending on gestational age, approximately $30 \%-50 \%$ of cardiac output perfuses the placenta, so $30 \%-50 \%$ of venous return comes from the placenta. ${ }^{30}$ As most of the oxygenated blood from the placenta is preferentially shunted through the foramen ovale towards the left atrium, preload for the left ventricle is largely dependent on placental venous return in the fetus. At birth, lung aeration results in an acute decrease of pulmonary vascular resistance and a simultaneous increase in pulmonary blood flow. This increase in pulmonary blood flow allows pulmonary venous return to take over from placental venous return as the major supplier of preload for the left ventricle.

Recent experimental studies in lambs indeed demonstrated that clamping of the umbilical cord prior to ventilation leads to a sudden decrease in left ventricular cardiac output. This results in unstable haemodynamic parameters with an initial reflexive increase in carotid arterial flow and pressure, followed by a decrease in carotid arterial flow and pressure and heart rate. ${ }^{67}$ In contrast, when lambs were first ventilated and subsequently clamped, systemic and cerebral haemodynamic parameters remained stable and led to higher systemic and cerebral oxygen saturation when compared with clamping before ventilation. ${ }^{7}$ It is possible that the observed beneficial clinical effect in preterm infants (less IVH and NEC) can be more ascribed to this stable haemodynamic effect than to placental transfusion.

These lamb studies indicate that timing of umbilical cord clamping must be guided by physiological parameters, rather than an arbitrary period after birth. To accomplish lung aeration before the cord is clamped, preterm infants should be stabilised while the cord remains intact, and cord clamping should be integrated in the stabilisation process. ${ }^{31}$ This so-called physiological-based cord clamping leads to a more gradual haemodynamic transition and may take longer than the predefined times used so ar. $^{26}$ Continuous assessment of the transition of the infant by the neonatologist will identify the optimal moment of cord clamping. Although PBCC might seem a logical approach, 


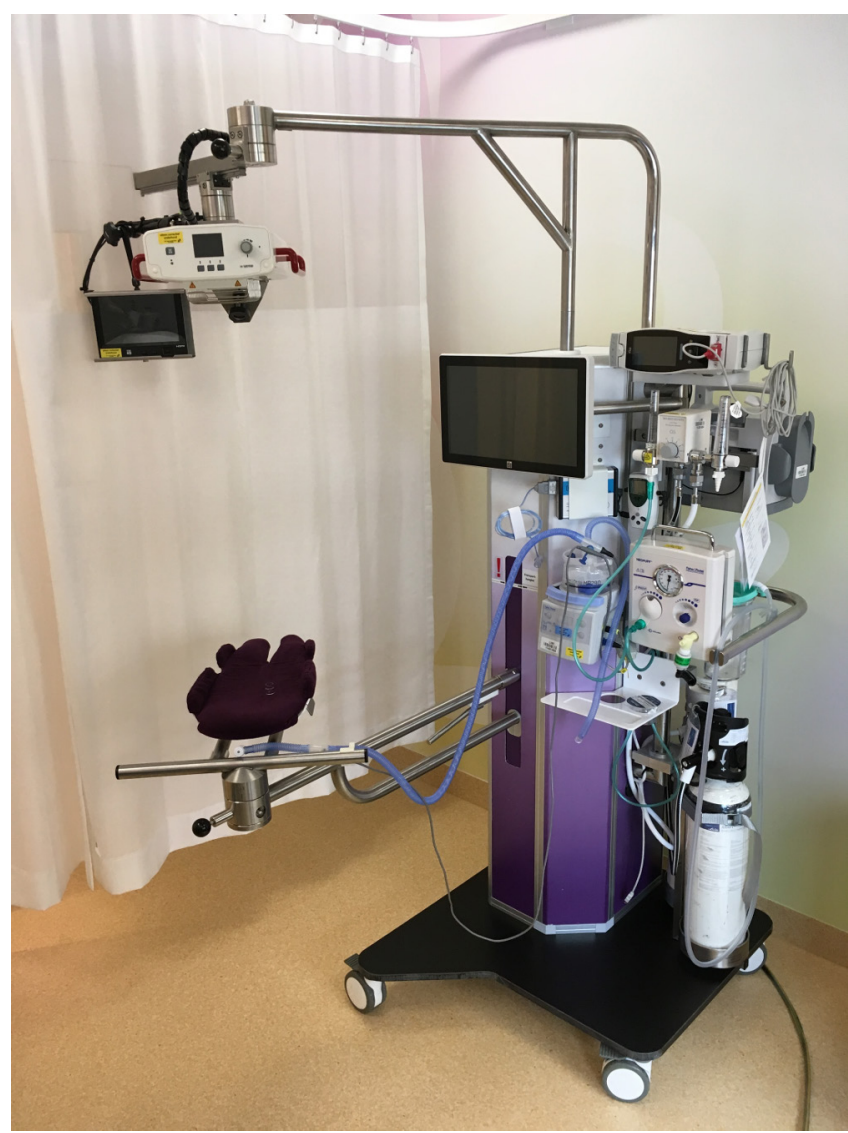

Figure 1 Specially designed new resuscitation table, including the platform for the infant, which can be turned above the mother's pelvis. The table is fully equipped to provide complete standard care and has a respiratory function monitor built in.

numerous practical issues, as well as potential pitfalls, need to be addressed before implementation of PBCC is possible.

\section{PRACTICAL CONSIDERATIONS}

\section{Stabilisation of preterm infants}

Respiratory strategies in delivery room management have changed in recent years. Studies have shown that most preterm infants can be stabilised using non-invasive respiratory support. ${ }^{15}$ Normograms have been developed for pulse oximetry and heart rate in preterm infants with and without respiratory support, but to determine the time point when a preterm infant is stable is not well defined in the literature. ${ }^{32} 33$ Most preterm infants start breathing within the first minute of life, but the effort is most often not efficient enough to establish lung aeration. ${ }^{34}$ Measuring tidal volumes during spontaneous breathing and positive pressure ventilation using a respiratory function monitor might help the clinician to assess the infant's condition. ${ }^{3536}$ Also, measuring expired $\mathrm{CO}_{2}$ can provide additional information about alveolar ventilation and the presence of pulmonary gas exchange in the newborn lung, rather than ventilation of dead space. ${ }^{37}$

For performing PBCC, it is necessary to continuously assess the cardiorespiratory condition of the infant to decide about the optimal timing of umbilical cord clamping. When the infant is spontaneously breathing with adequate tidal volumes and has adequate oxygenation that allows the fractional inspired oxygen $\left(\mathrm{FiO}_{2}\right)$ to be decreased, this informs the clinician that lung aeration has occurred and that pulmonary blood flow has increased.
At that moment, the infant's respiratory function is stable, and the cord can be clamped with minimal haemodynamic disturbances.

\section{Handling the cord}

When incorporating cord clamping into stabilisation of preterm infants, it is imperative that the cord is not kinked nor stretched during the procedure. The length of the umbilical cord is the most important limiting factor and is highly variable between infants. ${ }^{38}$ Mean umbilical cord length for term infants ranges between $50 \mathrm{~cm}$ and $60 \mathrm{~cm}$, but variation is substantial. ${ }^{39} 40$ For very preterm infants, the available data are scarce, and total length of the cord mostly ranges between $35 \mathrm{~cm}$ and $50 \mathrm{~cm} .{ }^{41} \mathrm{In}$ a practical application of PBCC, neonatal caregivers must be able to approach the mother and the birth canal as close as possible in order to include infants with a short umbilical cord.

\section{Unobstructed work fields}

Quality improvement projects implementing DCC in clinical practice have shown good feasibility and improvement in clinical outcomes. ${ }^{42}$ A multidisciplinary team approach, including key leadership from the obstetric and neonatal departments, is an important factor for successful implementation of PBCC. ${ }^{43}$ Obstetrical and neonatal clinical teams are literally merged at the bedside of the mother, requiring univocal agreements in the prescribed protocol. Next to training the teams on the new approach, briefing and debriefing with the entire team before and after each procedure is essential. Continuous communication between all members of the teams is pivotal to optimise the procedure and to minimise the risks.

The approach of PBCC requires unobstructed work fields for both obstetrical and neonatal caregivers. During the procedure, the obstetrical team must have good access to the mother to assess maternal blood loss and uterine contractions. Specifically, in case of caesarean delivery, blood loss must be monitored continuously. In case of twin delivery, it is important to monitor the condition of the second twin after the first one is born, so access to the mother's abdomen with ultrasound must be possible. The neonatal team must be able to give appropriate respiratory support to the preterm infant with the cord intact without obstructing the obstetrical team. This is possible near the mother's introitus, but probably more convenient and less obstructive just above the maternal pelvis.

Hypothermia increases the risk of morbidity and mortality for preterm infants, and adequate temperature management is essential during stabilisation and transfer to the neonatal intensive care unit. The implementation of DCC in clinical practice did not show an increase in the incidence of hypothermia. ${ }^{18}$ If the stabilisation includes normal precautions on heat loss prevention (body wraps, caps, radiant warmers and/or exothermic matresses), the risk of hypothermia should not be increased. ${ }^{44}$

\section{Family-centred care}

A preterm delivery is a stressful event for parents, especially when the infant is separated from the mother immediately after birth. ${ }^{45}$ The first mother-to-child contact, which is possible during PBCC, may be essential for short-term and long-term bonding. Research on the effect of very preterm birth and the given care on parents' experiences is ongoing.

\section{CURRENT APPROACHES OF STABILISATION WITH INTACT UMBILICAL CORD}

So far, only a few clinical studies investigating respiratory support in preterm infants prior to cord clamping have been performed. 


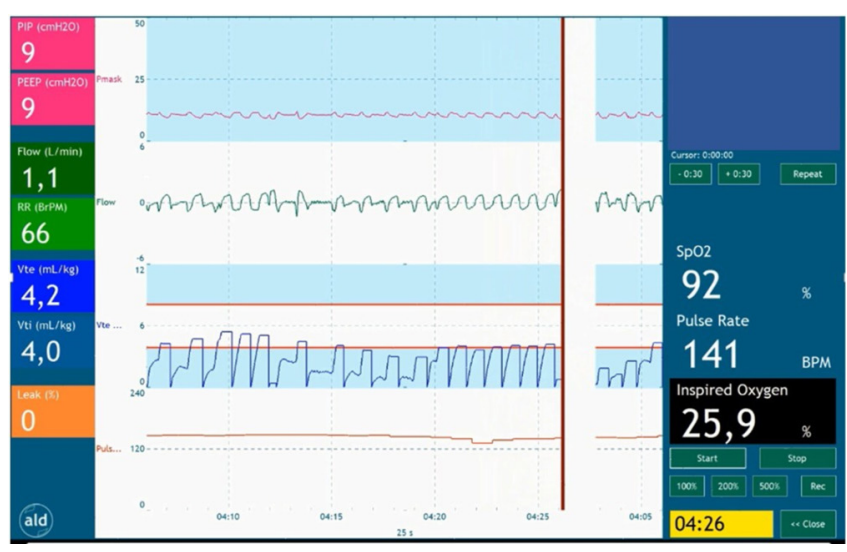

Figure 2 Respiratory function monitor depicting the respiratory function, oxygen saturation and heart rate; thus, providing feedback on the infant's transitional status. The timing of cord clamping is after the establishment of regular spontaneous breathing evaluated on the respiratory function monitoring, together with heart rate above 100 bpm and oxygen saturation above $90 \%$ while using $\mathrm{FiO}_{2}<40 \%$. $\mathrm{FiO}_{2}$, fractional inspired oxygen.

The feasibility was reported in a pilot study of 29 very preterm infants. ${ }^{46}$ Infants received respiratory support during $90 \mathrm{~s}$ after birth with the umbilical cord intact without maternal or neonatal safety concerns. Resuscitation beside the mother's hip was not possible in vaginal deliveries due to the length of the umbilical cord, so resuscitation was then started near the introitus. Feasibility was confirmed in a randomised clinical trial of 150 very preterm infants born by caesarean section randomised to DCC $(60 \mathrm{~s})$ in combination with ventilation while connected to the placenta (V-DCC) or without ventilation. ${ }^{47} \mathrm{~V}$-DCC was feasible in $78 \%$ of infants, but it did not lead to any measurable clinical improvement immediately after delivery or reduced subsequent neonatal morbidity. In the cord trial, very preterm infants were randomised between ICC within $20 \mathrm{~s}$ and deferred cord clamping for at least 2 min with neonatal care started at the bedside. ${ }^{48}$ There were no statistical differences in clinical outcomes, but the study was a continued pilot study and not powered to detect clinical differences. In $40 \%$ of infants allocated to the DCC group, cord clamping was performed earlier with most of them close to $20 \mathrm{~s}$. The infants were not monitored, and no information was available whether the infants could be adequately stabilised or were stable at the time of cord clamping. In summary, the current experience is that due to technical limitations of the available devices, it is certainly not always possible to perform stabilisation with intact umbilical cord.

An important consideration is that all aforementioned approaches used a predefined fixed time period for providing respiratory support prior to clamping of the cord. Hence, the rationale for most of these studies was to allow for placental transfusion. The transitional condition of the individual infant was not used in determining the optimal moment of cord clamping, and physiological parameters were not measured and collected. We speculate that this could provide an explanation for the lack of effect of these approaches. We therefore advocate that future studies adopt a physiological-based approach to determine the optimal timing of cord clamping.

\section{AERATION, BREATHING AND THEN CLAMPING (ABC)}

To improve transition in preterm infants and to perform PBCC, the $\mathrm{ABC}$ project was initiated in Leiden University Medical
Centre (Leiden, The Netherlands). A collaborative initiative of the neonatal, obstetric and medical engineering departments has resulted in a specially designed resuscitation table (figure 1). The new table has a platform for the infant, which can be turned above the mother's pelvis and allows the infant to be kept close to the mother without stretching the umbilical cord. The table is fully equipped to provide complete standard care. An integrated respiratory function monitor depicting the respiratory function, oxygen saturation and heart rate provides feedback on the infant's transitional status (figure 2). In this way, it is possible to delay cord clamping until the preterm infant has been stabilised. 'Stabilised' is defined as the establishment of regular spontaneous breathing evaluated on the respiratory function monitor, heart rate above $100 \mathrm{bpm}$ and oxygen saturation above $90 \%$ while using $\mathrm{FiO}_{2}<40 \%$. Using this $\mathrm{ABC}$ approach will result in true PBCC, as the infant's physiological status prescribes the timing of cord clamping. It will also allow the mother to have the essential immediate first (physical) contact with her baby. At this moment, results of the feasibility study are under review, and infants are included for the efficacy study.

\section{SUMMARY}

To improve transition in preterm infants, recent initiatives have been focusing on starting respiratory support prior to umbilical cord clamping. Although experimental studies have shown positive effects, clinical data are still needed. Incorporating cord clamping into stabilisation of preterm infants could lead to a more optimal placental transfusion and a more gradual haemodynamic transition. The moment of cord clamping should be based on the infant's transitional status as key determinant. Moreover, infants needing stabilisation or resuscitation can be included and will be able to benefit from the placental transfusion and PBCC. We hypothesise that this approach will result in optimal timing of cord clamping and thus will be able to reduce major morbidities and mortality in preterm infants. Further clinical studies are needed to establish the beneficial effect of PBCC in preterm infants.

Contributors RK wrote the first draft of the manuscript. All authors contributed by modifying and editing the manuscript. RK and ABtP processed the final remarks and accounted for the final version of the manuscript.

Funding $A B t P$ is recipient of a Netherlands Organisation for Scientific Research (NWO) innovational research incentives scheme (VIDI 91716428).

\section{Competing interests None declared.}

Provenance and peer review Not commissioned; externally peer reviewed.

Open access This is an open access article distributed in accordance with the Creative Commons Attribution Non Commercial (CC BY-NC 4.0) license, which permits others to distribute, remix, adapt, build upon this work non-commercially, and license their derivative works on different terms, provided the original work is properly cited and the use is non-commercial. See: http://creativecommons.org/ licenses/by-nc/4.0/

(c) Article author(s) (or their employer(s) unless otherwise stated in the text of the article) 2018. All rights reserved. No commercial use is permitted unless otherwise expressly granted.

\section{REFERENCES}

1 Sweet DG, Carnielli V, Greisen G, et al. European Consensus Guidelines on the Management of Respiratory Distress Syndrome - 2016 Update. Neonatology 2017;111:107-25.

2 Wyllie J, Bruinenberg J, Roehr CC, et al. European Resuscitation Council Guidelines for Resuscitation 2015: Section 7. Resuscitation and support of transition of babies at birth. Resuscitation 2015;95:249-63.

3 Katheria AC, Lakshminrusimha S, Rabe $\mathrm{H}$, et al. Placental transfusion: a review. J Perinatol 2017:37:105-11.

4 Hooper SB, Te Pas AB, Lang J, et al. Cardiovascular transition at birth: a physiological sequence. Pediatr Res 2015;77:608-14 
5 Vento M, Lista G. Managing preterm infants in the first minutes of life. Paediatr Respir Rev 2015;16:151-6.

6 Bhatt S, Alison BJ, Wallace EM, et al. Delaying cord clamping until ventilation onset improves cardiovascular function at birth in preterm lambs. J Physio 2013;591:2113-26.

7 Polglase GR, Dawson JA, Kluckow M, et al. Ventilation onset prior to umbilical cord clamping (physiological-based cord clamping) improves systemic and cerebral oxygenation in preterm lambs. PLoS One 2015;10:e0117504.

8 O'Donnell CP, Stenson BJ. Respiratory strategies for preterm infants at birth. Semin Fetal Neonatal Med 2008:13:401-9.

9 Hooper SB, Polglase GR, te Pas AB. A physiological approach to the timing of umbilical cord clamping at birth. Arch Dis Child Fetal Neonatal Ed 2015;100:F355-60.

10 Niermeyer S. A physiologic approach to cord clamping: Clinical issues. Matern Health Neonatol Perinatol 2015;1:21.

11 Farrar D, Tuffnell D, Airey R, et al. Care during the third stage of labour: a postal survey of UK midwives and obstetricians. BMC Pregnancy Childbirth 2010;10:23.

12 Begley CM, Gyte GM, Devane D, et al. Active versus expectant management for women in the third stage of labour. Cochrane Database Syst Rev 2015:3:CD007412.

13 McDonald SJ, Middleton P, Dowswell T, et al. Effect of timing of umbilical cord clamping of term infants on maternal and neonatal outcomes. Cochrane Database Syst Rev 2013;7:CD004074.

14 Yao AC, Moinian M, Lind J. Distribution of blood between infant and placenta after birth. Lancet 1969:2:871-3.

15 WHO. Guideline: Delayed umbilical cord clamping for improved maternal and infant health and nutrition outcomes. Geneva: World Health Organization, 2014.

16 Chiruvolu A, Tolia VN, Qin H, et al. Effect of delayed cord clamping on very preterm infants. Am J Obstet Gynecol 2015:213:676 e1-7.

17 Backes $\mathrm{CH}$, Huang $\mathrm{H}$, lams JD, et al. Timing of umbilical cord clamping among infants born at 22 through 27 weeks' gestation. J Perinatol 2016;36:35-40.

18 Rabe H, Diaz-Rossello JL, Duley L, et al. Effect of timing of umbilical cord clamping and other strategies to influence placental transfusion at preterm birth on maternal and infant outcomes. Cochrane Database Syst Rev 2012;8:CD003248.

19 Tarnow-Mordi W, Morris J, Kirby A, et al. Delayed versus Immediate Cord Clamping in Preterm Infants. N Engl J Med 2017;377:2445-55.

20 Fogarty M, Osborn DA, Askie L, et al. Delayed vs early umbilical cord clamping for preterm infants: a systematic review and meta-analysis. Am J Obstet Gynecol 2018;218:1-18

21 Hooper SB, Crossley KJ, Zahra VA, et al. Effect of body position and ventilation on umbilical artery and venous blood flows during delayed umbilical cord clamping in preterm lambs. Arch Dis Child Fetal Neonatal Ed 2017;102:F312-F9.

22 Hooper SB, Polglase GR, Roehr CC. Cardiopulmonary changes with aeration of the newborn lung. Paediatr Respir Rev 2015;16:147-50.

23 Yao AC, Lind J. Effect of gravity on placental transfusion. Lancet 1969;2:505-8.

24 Vain NE, Satragno DS, Gorenstein AN, et al. Effect of gravity on volume of placental transfusion: a multicentre, randomised, non-inferiority trial. Lancet 2014:384:235-40.

25 Al-Wassia H, Shah PS. Efficacy and safety of umbilical cord milking at birth: a systematic review and meta-analysis. JAMA Pediatr 2015;169:18-25.

26 Blank DA, Polglase GR, Kluckow M, et al. Haemodynamic effects of umbilical cord milking in premature sheep during the neonatal transition. Arch Dis Child Fetal Neonatal Ed 2017:F1-F8.
27 Katheria AC, Brown MK, Rich W, et al. Providing a Placental Transfusion in Newborns Who Need Resuscitation. Front Pediatr 2017:5:1

28 Hooper SB, Binder-Heschl C, Polglase GR, et al. The timing of umbilical cord clamping at birth: physiological considerations. Matern Health Neonatol Perinatol 2016:2:4

29 Gao Y, Raj JU. Regulation of the pulmonary circulation in the fetus and newborn. Physiol Rev 2010;90:1291-335.

30 Wu TW, Azhibekov T, Seri I. Transitional Hemodynamics in Preterm Neonates: Clinical Relevance. Pediatr Neonatol 2016:57:7-18.

31 Niermeyer S, Velaphi S. Promoting physiologic transition at birth: re-examining resuscitation and the timing of cord clamping. Semin Fetal Neonatal Med 2013;18:385-92.

32 Dawson JA, Kamlin CO, Vento M, et al. Defining the reference range for oxygen saturation for infants after birth. Pediatrics 2010;125:e1340-7.

33 Dawson JA, Kamlin CO, Wong C, et al. Oxygen saturation and heart rate during delivery room resuscitation of infants $<30$ weeks' gestation with air or $100 \%$ oxygen. Arch Dis Child Fetal Neonatal Ed 2009;94:F87-91.

34 Huberts TJP, Foglia EE, Narayen IC, et al. The Breathing Effort of Very Preterm Infants at Birth. J Pediatr 2018;194:54-9.

35 Schmölzer GM, Morley CJ, Wong C, et al. Respiratory function monitor quidance of mask ventilation in the delivery room: a feasibility study. J Pediatr 2012;160:377-81.

36 van Vonderen JJ, Roest AA, Siew ML, et al. Measuring physiological changes during the transition to life after birth. Neonatology 2014;105:230-42.

37 Ngan AY, Cheung PY, Hudson-Mason A, et al. Using exhaled $\mathrm{CO}_{2}$ to guide initial respiratory support at birth: a randomised controlled trial. Arch Dis Child Fetal Neonatal Ed 2017;102:F525-F31.

38 Malpas P. Length of the human umbilical cord at term. Br Med J 1964;1:673-4

39 Moessinger AC, Blanc WA, Marone PA, et al. Umbilical cord length as an index of fetal activity: experimental study and clinical implications. Pediatr Res 1982;16:109-12.

40 Yamamoto Y, Aoki S, Oba MS, et al. Relationship Between Short Umbilical Cord Length and Adverse Pregnancy Outcomes. Fetal Pediatr Pathol 2016;35:81-7.

41 Walker CW, Pye BG. The length of the human umbilical cord: a statistical report. $\mathrm{Br}$ Med J 1960; 1:546-8.

42 Ruangkit C, Moroney V, Viswanathan S, et al. Safety and efficacy of delayed umbilical cord clamping in multiple and singleton premature infants - A quality improvement study. J Neonatal Perinatal Med 2015:8:393-402.

43 Bolstridge J, Bell T, Dean B, et al. A quality improvement initiative for delayed umbilica cord clamping in very low-birthweight infants. BMC Pediatr 2016;16:155.

$44 \mathrm{McCall}$ EM, Alderdice F, Halliday HL, et al. Interventions to prevent hypothermia at birth in preterm and/or low birthweight infants. Cochrane Database Syst Rev 2010;3:CD004210.

45 Sawyer A, Rabe H, Abbott J, et al. Parents' experiences and satisfaction with care during the birth of their very preterm baby: a qualitative study. BJOG 2013;120:637-43.

46 Winter J, Kattwinkel J, Chisholm C, et al. Ventilation of Preterm Infants during Delayed Cord Clamping (VentFirst): A Pilot Study of Feasibility and Safety. Am J Perinatol 2017;34:111-6.

47 Katheria A, Poeltler D, Durham J, et al. Neonatal Resuscitation with an Intact Cord: A Randomized Clinical Trial. J Pediatr 2016:178:75-80.

48 Duley L, Dorling J, Pushpa-Rajah A, et al. Randomised trial of cord clamping and initial stabilisation at very preterm birth. Arch Dis Child Fetal Neonatal Ed 2018;103:F6-F14. 